\title{
TMF test based validation of numerical methods for the analysis of heat-loaded walls
}

\author{
A. Gernoth ${ }^{*}$, M. Wurdak ${ }^{\dagger}$, J. R. Riccius ${ }^{\ddagger}$ and S. Schlechtriem ${ }^{\S}$ \\ DLR Lampoldshausen, Hardthausen, Germany, 74239 \\ and \\ D. Wiedmann ${ }^{* *}$, W. Schwarz ${ }^{\dagger \dagger}$ and L. Brummer" \\ EADS Astrium Space Transportation, Munich, Germany, 81663
}

\begin{abstract}
The creation of validation data for CFD, thermal, structural and life time analyses of actively cooled thermally loaded wall structures of rocket engines by means of ThermoMechanical Fatigue (TMF) - tests is discussed in this paper. During a TMF test, only a small section of the hot gas wall of the real engine (the so called TMF panel) is tested. For such a TMF panel, realistic cooling conditions similar to a full scale rocket engine are chosen. The 2d measurement of the thermal field of the heat loaded structure provides (together with the measurement of the temperature, pressure and mass flow rate of the coolant of the TMF panel) data for the combined validation of the CFD analysis of the coolant flow and the thermal analysis of the wall structure. The measurement of the deformation of the thermally loaded structure provides (together with the already determined temperature distribution and the above mentioned pressure measurements of the cooling channels) data for the validation of the structural analysis of the thermally loaded structure. Counting the number of laser loading cycles (laser on-off) until the TMF panel fails (by cracks appearing on the laser loaded side of the cooling channels) provides data for the validation of (either post processing or damage parameter based) life time analyses of thermally loaded structures.
\end{abstract}

\section{Introduction}

The strong demand for light-weight structures, which is typical for space transportation systems, leads to a closeto-the-limit design of all involved components - including the rocket engines. The hot walls of combustion chambers and nozzle extensions often represent the most critical components of a rocket engine due to the severe thermomechanical loads they are exposed to during operation. The development and flight qualification of such components includes in line with many other actions CFD and Finite Element analyses of the key components and full scale tests of the whole rocket engine. Thermo-Mechanical Fatigue (TMF) tests can provide essential validation data for these numerical analyses and may even help to reduce the need for full scale tests considerably. Therefore, TMF tests have the potential of both, avoiding failure due to non-validated design analyses as well as saving full scale testing cost.

\footnotetext{
* PhD student, Fluids \& Structures Group, Technology Department, 74239 Hardthausen, Germany.

${ }^{\dagger}$ Bachelor student, Fluids \& Structures Group, Technology Department, 74239 Hardthausen, Germany.

* Head of Fluids \& Structures Group, Technology Department, 74239 Hardthausen, Germany, AIAA member.

${ }^{\S}$ Head of Institute of Space Propulsion, 74239 Hardthausen, Germany, AIAA member.

${ }^{* *}$ Development Engineer, System Analysis, EADS Astrium Space Transportation, 81663 Munich, Germany.

ti Development Engineer, System Analysis, EADS Astrium Space Transportation, 81663 Munich, Germany.

\# Development Engineer, Advanced Programs, EADS Astrium Space Transportation, 81663 Munich, Germany.
} 


\section{Validation possibilities for CFD, thermal, structural and life time analyses}

CFD and Finite Element models of actively cooled thermally loaded wall structures can be validated by a series of measurements. A list of measurements that are possible for both, (model, subscale or full scale) combustion chamber tests as well as for TMF tests are given in Table 1.

Table 1: Validation possibilities for numerical analyses of TMF panels and combustion chamber walls.

\begin{tabular}{|c|c|c|c|}
\hline analysis type & $\begin{array}{l}\text { physical } \\
\text { parameter }\end{array}$ & measurement location & measurement device \\
\hline \multirow{4}{*}{$\begin{array}{l}\text { coupled CFD analysis of } \\
\text { the coolant flow and } \\
\text { thermal analysis of the } \\
\text { wall structure }\end{array}$} & $\begin{array}{l}\text { coolant } \\
\text { pressure }\end{array}$ & $\begin{array}{l}\text { single spot(s) in the cooling channels } \\
\text { upstream and downstream of the laser loaded } \\
\text { area of the TMF panel }\end{array}$ & pressure sensor(s) \\
\hline & $\begin{array}{l}\text { coolant } \\
\text { temperature }\end{array}$ & single spot(s) in the cooling channels & thermocouple(s) \\
\hline & $\begin{array}{l}\text { coolant mass } \\
\text { flow rate }\end{array}$ & single spot(s) in the fluid system & mass flow meter(s) \\
\hline & \begin{tabular}{|l|} 
temperature \\
inside the \\
structure
\end{tabular} & single $\operatorname{spot}(\mathrm{s})$ in the thermally loaded structure & thermocouple(s) \\
\hline \multirow[t]{2}{*}{$\begin{array}{l}\text { structural analysis of the } \\
\text { wall structure }\end{array}$} & deformation & $\begin{array}{l}\text { displacement }\left(\mathrm{u}_{\text {normal }}\right) \text { normal to the surface of } \\
\text { the thermally loaded structure on single lines } \\
\text { before and after the test }\end{array}$ & perthometer \\
\hline & & $\begin{array}{l}2 \mathrm{~d} 1 \text {-component displacement }\left(\mathrm{u}_{\text {normal }}\right) \text { normal } \\
\text { to the surface of the thermally loaded } \\
\text { structure before and after the test }\end{array}$ & $\begin{array}{l}\text { laser scanning } \\
\text { microscope }\end{array}$ \\
\hline $\begin{array}{l}\text { life time analysis of the } \\
\text { wall structure (either post } \\
\text { processing based }{ }^{1} \text { or } \\
\text { damage parameter based }^{2} \text { ) }\end{array}$ & \multicolumn{3}{|c|}{$\begin{array}{l}\text { number of laser loading cycles (laser on-off) until the TMF panel fails } \\
\text { (by cracks appearing on the laser loaded side of the cooling channels) }\end{array}$} \\
\hline
\end{tabular}

On top of the measurement capabilities given in Table 1, the laser heating of the TMF panel provides - in comparison with (model, subscale or full scale) combustion chamber hot run tests - three unique features UF1, UF2 and UF3:

$>$ The direct determination of the heat flux into the thermally loaded side of the structure (by means of a laser power measurement and the determination of the absorption of the laser loaded surface at the hot run temperature of the TMF panel) is considered as the $1^{\text {st }}$ unique feature UF1 of TMF panel tests, because for hot run tests with combustion chambers, this heat flux can be determined only indirectly - e.g. by means of the measurement of the heating of the coolant (which might lead to high measurement errors in case the temperature increase of the coolant is small) or by means of temperature measurements in different radial positions of the chamber wall (which might for high heat fluxes lead to high measurement errors due to positioning inaccuracies of the thermocouples) or by means of heat flux sensors (which might lead to high measurement errors due to insufficient contact of the heat flux sensor with the remaining structure). The laser power measurement provides (together with mass flow, pressure and temperature measurements of the coolant) the boundary conditions for a coupled CFD and thermal analysis of the TMF panel.

The two dimensional measurement of the temperature on the laser heated side of the TMF panel by means of an infra red camera is considered as the $2^{\text {nd }}$ unique feature UF2 of TMF panel tests because hot run tests with combustion chambers would allow for only point wise temperature measurements by means of 
thermocouples. This provides essentially improved validation data for coupled CFD and thermal analyses of thermally loaded structures.

$>$ The measurement of a $2 d$ field of all of the three deformation components $\left(u_{x}, u_{y}, u_{z}\right)$ of the thermally loaded structure during the hot run by means of speckle marks on the structure and a stereoscopic camera system is considered as the $3^{\text {rd }}$ unique feature UF3 of TMF panel tests, because for hot run tests with a combustion chamber, only the following restricted deformation measurements are possible:

- out-of-plane deformation measurement only (deformation component measurement restriction)

- only measurements before and after (but not during) the hot run

Therefore, UF3 as well provides essentially improved validation data for structural analyses of thermally loaded structures.

In Table 2, the three above mentioned unique features and validation possibilities for the numerical analyses of TMF panel tests are summarized.

Table 2: Unique features of TMF tests (which are not possible for combustion chamber tests).

\begin{tabular}{|c|c|c|c|c|c|}
\hline $\begin{array}{l}\text { analysis } \\
\text { type }\end{array}$ & physical paramete & & $\begin{array}{l}\text { measurement } \\
\text { location and/or } \\
\text { time }\end{array}$ & measurement device & $\begin{array}{l}\text { unique } \\
\text { feature } \\
\text { number }\end{array}$ \\
\hline \multirow{3}{*}{$\begin{array}{l}\text { coupled } \\
\text { CFD } \\
\text { analysis of } \\
\text { the coolant } \\
\text { flow and } \\
\text { thermal } \\
\text { analysis of } \\
\text { the } \\
\text { structure }\end{array}$} & \multirow{2}{*}{$\begin{array}{l}\text { heat flux through } \\
\text { the thermally } \\
\text { loaded surface of } \\
\text { the structure }\end{array}$} & $\begin{array}{l}\text { total laser beam } \\
\text { power }\end{array}$ & laser beam & laser power meter & \multirow[t]{2}{*}{ UF1 } \\
\hline & & $\begin{array}{l}\text { absorption of } \\
\text { the surface of } \\
\text { the TMF panel } \\
\text { at the panel test } \\
\text { temperature }\end{array}$ & $\begin{array}{ll}\text { laser } & \text { loaded } \\
\text { surface } & \end{array}$ & $\begin{array}{l}\text { combination of thermocouples } \\
\text { and a high precision pyrometer } \\
\text { with spectral range equal to the } \\
\text { laser wave length }\end{array}$ & \\
\hline & \multicolumn{2}{|c|}{ 2d temperature field } & $\begin{array}{l}\text { surface of the laser } \\
\text { heated side of the } \\
\text { TMF Panel }\end{array}$ & infra red camera & UF2 \\
\hline $\begin{array}{l}\text { structural } \\
\text { analysis }\end{array}$ & \multicolumn{2}{|c|}{$\begin{array}{l}2 \mathrm{~d}, 3 \text { component deformation field } \\
\left(\mathrm{u}_{\mathrm{x}}, \mathrm{u}_{\mathrm{y}}, \mathrm{u}_{\mathrm{z}}\right)\end{array}$} & $\begin{array}{l}\text { laser heated side } \\
\text { during the hot run } \\
\text { and the cold flow }\end{array}$ & $\begin{array}{l}\text { stereo camera system (requires } \\
\text { speckle marks on the surface of } \\
\text { the TMF panel) }\end{array}$ & UF3 \\
\hline
\end{tabular}

\section{Components of the TMF test facility at DLR Lampoldshausen}

\section{A. The heating device of the TMF test facility}

The key component of a TMF test bench is a heating device for the tested wall component. For medium heat flux applications and a rotatory symmetric test specimen design, a combination of quartz tube radiant heaters and parabolic mirrors have been used for jet engine Thermal Barrier Coating (TBC) tests ${ }^{3,4}$.

However, liquid propellant rocket engines are exposed to much higher heat flux densities compared to jet engines. Consequently, realizing relevant environmental conditions inside a TMF test bench requires much higher power densities compared to jet engine application. For example, even a local combustion process under ambient pressure does not necessarily provide the high energy density which is necessary

Table 3: Key technical parameters of the laser.

\begin{tabular}{|l|c|}
\hline parameter & value \\
\hline wavelength & $940 \mathrm{~nm}$ \\
\hline optical output power & $11 \mathrm{~kW}$ \\
\hline distance from the optics module to the focal plane & $415 \mathrm{~mm}$ \\
\hline plateau cross section of the beam at the focal plane & $19 \mathrm{~mm} \times 51 \mathrm{~mm}$ \\
\hline homogeneity & better than $\pm 5 \%$ \\
\hline operational mode & $\mathrm{cW}$ \\
\hline
\end{tabular}


for this purpose. Therefore, an optical heating device with a high energy density is required. The remaining options are high power lamps (available as metal halide $\operatorname{arc~lamps~}^{\S \S}$ or tungsten wire lamps ${ }^{* * *}$ up to $24 \mathrm{~kW}$ and as xenon arc lamps $s^{\dagger \dagger \dagger}$ up to $30 \mathrm{~kW}$ ) and high power laser systems, available on a variety of wave lengths.

The heating device of the TMF test bench at DLR Lampoldshausen was designed and built by DILAS Diodenlaser $\mathrm{GmbH}^{5,6}$. The key technical parameters of this diode laser are given in Table 3.

The laser source consists of 20 laser stack modules as shown in Figure 1 middle right. Grouping four of these stacks together yields to a standard industrial module used e.g. for laser welding. A combination of five of such standard modules with a beam shaping optics module finally results in the laser head as shown in Figure 1 right.

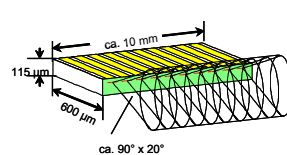

$\rightarrow$

10 laser diodes

combined with a cylindrical

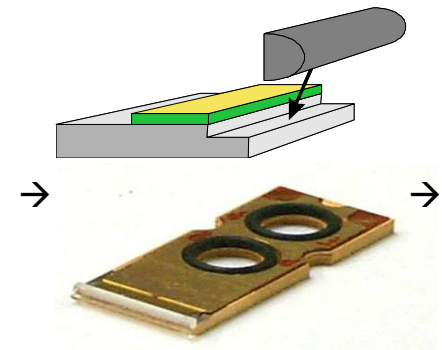
lens \& soldered to a cooled copper bar $=1$ laser bar

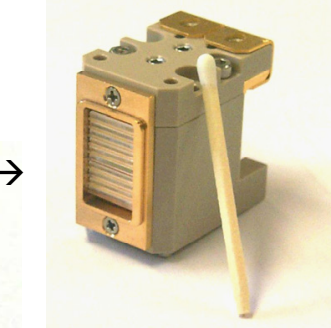

1 laser stack module

$=10$ stacked laser bars

$=100$ laser diodes

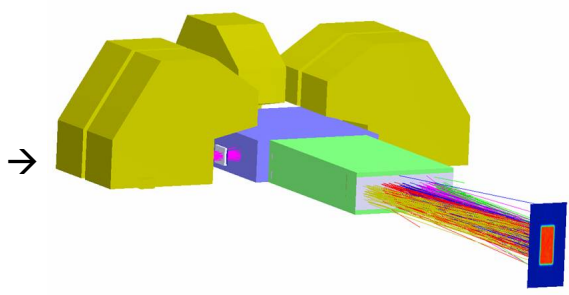

laser head inclusive beam shaping optics $=20$ laser stack modules = 200 laser bars $=2000$ laser diodes

Figure 1: Modular structure of the laser head: laser diodes (left), laser bar (middle left), laser stack module (middle right) and complete laser head including beam shaping optics (right).

The key components of the laser system - power supply \& control unit; laser head (including beam shaping optics) and cooler - are shown in Figure 2.

power supply \& control unit

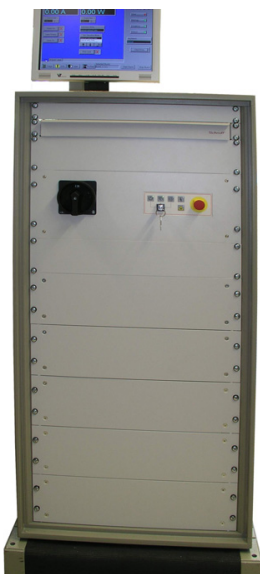

laser head

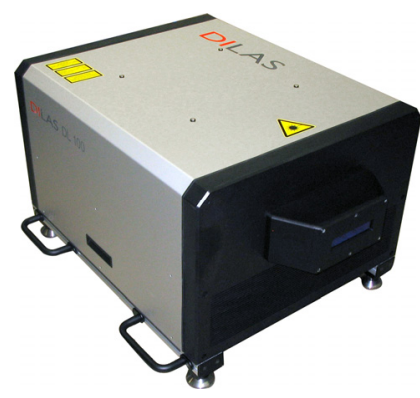

length: $1.5 \mathrm{~m}$ width: $0.82 \mathrm{~m}$ height: $1.94 \mathrm{~m}$ cooler

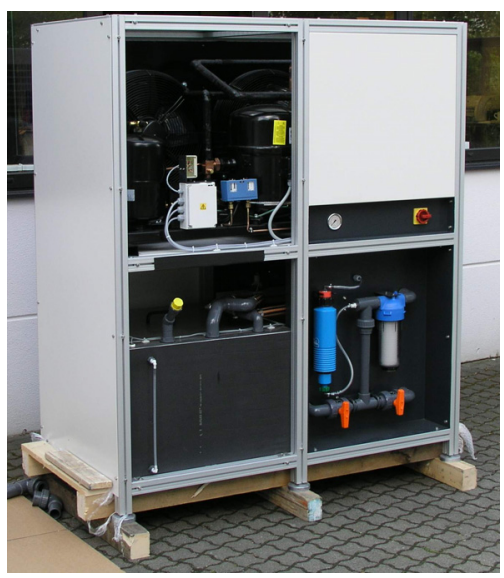

Figure 2: Components of the laser system: power supply \& control unit (left), laser head (middle) and cooler (right).

${ }^{\S}$ URL: http://www.arri.de/lighting/europe_asia_australia_africa/tungsten_lampheads/arri_studio_fresnel/ arri_studio_t24.html; [cited 16 July 2010]

${ }^{* * *}$ URL: http://www.osram.com/osram_com/Professionals/DisplayOptic_Lighting/Product_Overview/

Metal_Halide_Lamps/index.html; [cited 16 July 2010]

${ }^{\dagger \dagger}$ URL: http://www.ushio.nl/watercooled.html, [cited 16 July 2010] 
In order to check, whether the real intensity distribution of the laser beam at the focal plane coincides with a previously simulated intensity distribution as shown in Figure 3 left, 2 different tests were performed:

- The infra red laser light was transformed into visible light by a fluorescent sheet as shown in Figure 3 middle.

- The thermal energy of the laser was used to treat the surface of a plastic sheet as shown in Figure 3 right.


Figure 3. Simulation (left) and visualization of the intensity distribution of the laser beam at the focal plane with an infra red conversion screen (middle) and with burn-in marks on a plastic sheet (right) at low laser power.

In order to obtain the slight surface change in the upper part of the shown plastic sheet, a laser power of $80 \mathrm{~W}$ was applied for duration of $1 \mathrm{~s}$, whereas the stronger burn-in mark in the lower part of this plastic sheet was obtained by an exposure time of $1.5 \mathrm{~s}$ at a laser power of $150 \mathrm{~W}$.

\section{B. The TMF panel housing}

Without a panel housing, the following undesired effects could occur:

- Oxidation effects of the laser loaded side of the TMF panel wall due to a combination of high temperatures and the Oxygen content of air. Of course - such oxidation effects might occur in the real engine as well. However, in order to quantify these oxidation effects, different TMF panel tests with and without the presence of Oxygen should be performed.

- Water condensation effects on the laser loaded side of the TMF panel wall material during the pre- and post cooling processes due to the cryogenic temperature (160 $\mathrm{K})$ of the coolant (Nitrogen). This condensation effects



Figure 4: Left: laser head; Top: infra red camera; Right: TMF panel housing (side walls removed). 
could obstruct deformation measurement systems.

- Endangering TMF test bench personnel due to laser light, reflected by the TMF panel.

In order to avoid the above mentioned effects, a TMF panel housing as shown in Figure 4 was designed.

\section{The fluid system}

As the TMF panel is realistically heated, it also has to be cooled similar to the original structure. The fluid system of the TMF test bench provides the cooling fluid for this purpose.
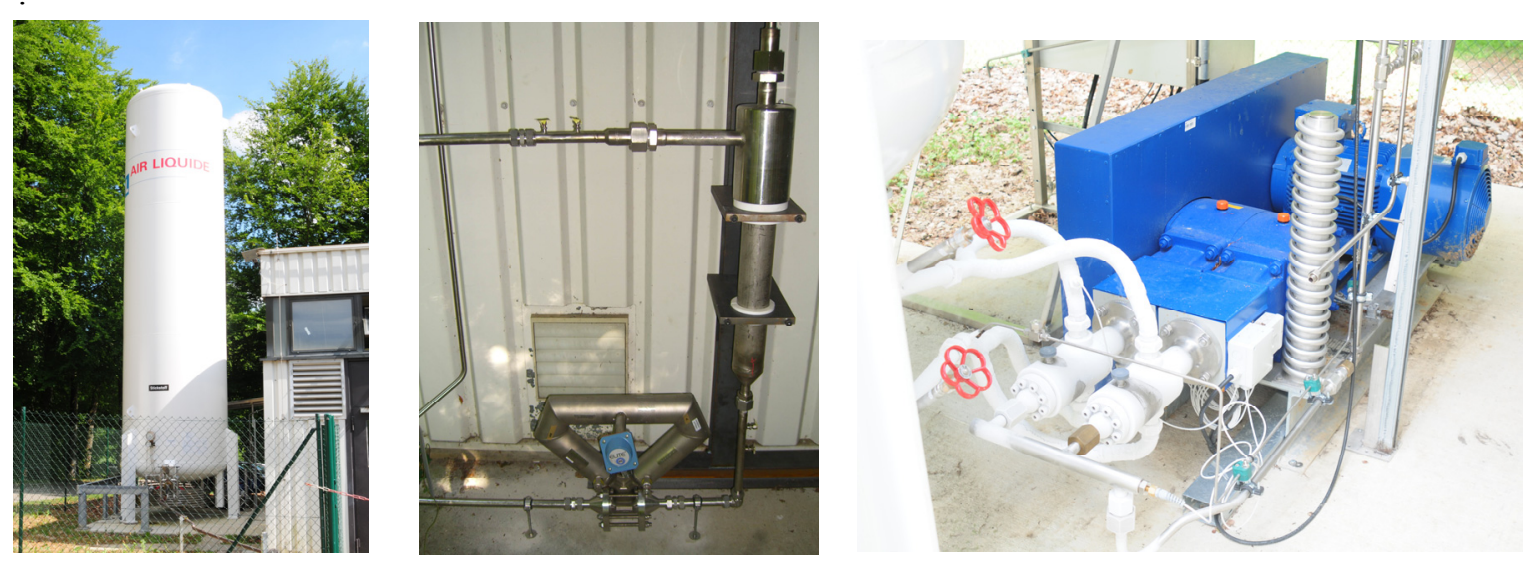

Figure 5: Liquid Nitrogen tank, mixer and cryogenic piston pump.

The temperature of the coolant can be fully controlled by means of a mixer as shown in Figure 5 middle. A cryogenic coolant proportion, stored in liquid phase in a tank as shown in Figure 5 left is mixed with a gaseous ambient temperature proportion of the coolant. The mass flow rate as well as the pressure of the fluid can be controlled by means of computer controlled valves. As the coolant is stored under low pressure in the liquid tank, a coolant pump as shown in Figure 5 right is necessary as well. For economical and safety reasons, Nitrogen was chosen as a coolant for the TMF panels, although the equivalent full scale structures are cooled by Hydrogen. The storage capacity of the vacuum insulated run tank is $21 \mathrm{~m}^{3} \mathrm{LN}_{2}$, its maximum pressure is 17 bars.

\section{The measurement and control system}

The main components of the measurement and control system of the TMF test facility are specified in Table 4. These components provide in connection with thermocouples, pressure sensors and Coriolis flow meters measurement capabilities for the TMF panel as well as for the fluid system on one side and allow for the fully automatic control of the valves of the fluid system and the laser power on the other side.

\section{E. The measurement devices}

1. Laser Power Meter

For the determination of the heat flux into the TMF Panel, the following values have to be measured:

$>$ the absorption of the laser loaded surface at the laser wave length (as described in section $\mathrm{V}$ ) and

$>$ the laser power in the focal plane.
Table 4: Main components of the measurement and control system of the TMF test facility.

\begin{tabular}{|l|l|l|}
\hline components & pieces & specification \\
\hline computers & 2 & $\begin{array}{l}\text { Intel Dual Core, 2.66 GHz, } \\
\text { 2 GB RAM, 160 GB HDD }\end{array}$ \\
\hline $\begin{array}{l}\text { measurement } \\
\text { cards }\end{array}$ & 3 & $\begin{array}{l}\text { NI PCI-6031E (16 bit): } \\
32 \text { differential channels, } 100 \mathrm{ks} / \mathrm{s}\end{array}$ \\
\hline control cards & 3 & $\begin{array}{l}\text { NI PCI-6259 (16 bit): } \\
8 \text { differential input channels, 1 MS/s, } \\
\text { 4 output channels (16 bit), 2.8 MS/s }\end{array}$ \\
\hline software & 2 & based on Lab VIEW 8.5 \\
\hline amplifiers & 40 & $\begin{array}{l}\text { AS4a (32) and AS2 (8) } \\
\text { (developed at DLR Lampoldshausen) }\end{array}$ \\
\hline
\end{tabular}


A special version of the PRIMES Power Monitor ${ }^{t+}$ with an aperture of $250 \mathrm{~mm}$ x $50 \mathrm{~mm}$ is used for the measurement of the laser power. For laser power values between $1 \mathrm{~kW}$ and $12 \mathrm{~kW}$, the measurement error of the system is better than $\pm 2 \%$ of the measured value ${ }^{7}$.

\section{Laser wave length pyrometer}

The absorption of the laser loaded surface at elevated temperatures is measured by a pyrometer with an identical wave length as the laser. This high end transfer standard pyrometer IMPAC IS12-TSP ${ }^{\S \S}$ allows for temperature measurements with an accuracy of $\pm 0.15 \%$ of the measured value $\pm 1{ }^{\circ} \mathrm{C}$ at a measurement range between $430{ }^{\circ} \mathrm{C}$ and $1300^{\circ} \mathrm{C}$ and is equipped with a special band pass filter with a center wave length of $940 \mathrm{~nm} \pm 4 \mathrm{~nm}$ and a half width of $20 \mathrm{~nm} \pm 4 \mathrm{~nm}$.

\section{Infra red camera}

The $2 \mathrm{~d}$ thermal field at the laser loaded side of the TMF panel is measured by an infra red camera ${ }^{* * * *}$ with a resolution up to $640 \times 512$ pixel, a maximum acquisition rate of $100 \mathrm{~Hz}$ and a measurement range of $300{ }^{\circ} \mathrm{C}$ to 1500 ${ }^{\circ} \mathrm{C}$. Related to a black body, the measurement error of this infra red camera is better than $\pm 1 \%$ of the measured temperature value. To avoid a possible influence of reflected laser light to the temperature measurement while the TMF Panel is loaded by the laser system, a high pass filter with a wavelength of $3.99 \mu \mathrm{m}$ is used.

\section{Deformation measurement system}

The deformation of the TMF panel is measured by an image correlation ${ }^{8}$ system $^{\dagger \dagger \dagger}$. In order to obtain the highest possible measurement accuracy, a system consisting of two 16 MPixel cameras ${ }^{\text {tht }}$ was selected. This measurement system requires the application of small speckle marks to the surface of the TMF panel and allows for the measurement of a $2 \mathrm{~d}, 3$ component $\left(\mathrm{u}_{\mathrm{x}}, \mathrm{u}_{\mathrm{y}}, \mathrm{u}_{\mathrm{z}}\right)$ displacement field on the surface of the TMF panel before, during and after the laser loading.

\section{The TMF panel}

A nozzle extension type TMF panel was designed and produced by ASTRIUM. In Figure 6, the middle part of this TMF panel is shown on its laser loaded side. Different types of TMF panels are described in references 9 to 11.

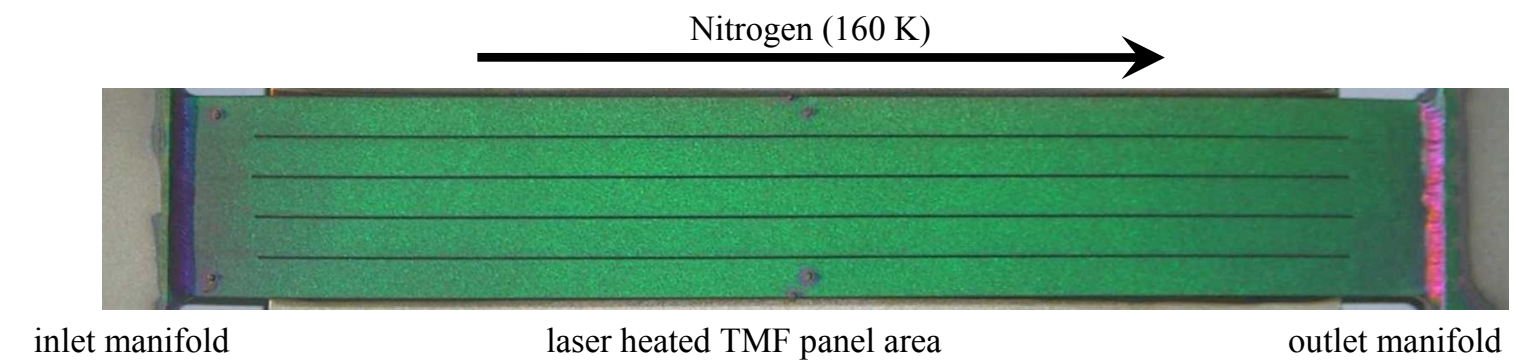

Figure 6: Nozzle extension type TMF panel.

In contrary to typical full scale engines, e.g. Vulcain 2, which are cooled by a small fraction of the propellant ("dump cooling") - this TMF panel is (for safety reasons) cooled with Nitrogen. The Nitrogen flow through the TMF panel is controlled to get a fixed temperature on the surface. This ensures the capability to make cyclic tests with constant temperatures on the surface as well as constant heat fluxes.

\footnotetext{
Ht URL: http://www.primes.de/download/produkte/f1_5_Datenblatt_PowerM_low.pdf, [cited 16 July 2010]

$\S \S$ URL: http://www.lumasenseinc.com/uploads/Impacinfrared/Datenblaetter_pdf/Pyrometer/

IS12-TSP_IGA12-TSP_e.pdf, [cited 16 July 2010]

${ }^{* * * *}$ URL: http://www.flir.com/uploadedFiles/Thermography_APAC/Products/Product_Literture/ 090901\%20SC7600MB.pdf [cited 16 July 2010]

†ो广 URL: http://www.limess.com/phocadownload/limess_leaflet_dic.pdf, [cited 16 July 2010]

Htt URL: http://www.alliedvisiontec.com/us/products/cameras/gigabit-ethernet/prosilica-ge/ge4900.html, [cited 16 July 2010]
} 
The absorption of typical nozzle extension materials such as nickel basis alloys is for smooth surfaces usually lower than $50 \%$ at the laser wavelength of $940 \mathrm{~nm}$. Therefore, a large proportion of the laser power would be reflected in case the laser is pointed directly to the TMF panel material. However, such a large reflection would cause both: a large thermal loading of all of the components of the TMF facility as well as an inefficient usage of the laser power. Therefore, a special coating was applied to the laser loaded surface of the TMF panel - visible as green color in the middle of Figure 6. The absorption of this coating is discussed in section V.

\section{A priori determination of the emissivity of the TMF panel coating}

\section{A. Test set-up}

The determination of the absorption of the laser loaded surface is of fundamental interest for both evaluating the heat flux into the TMF panel as well as for obtaining a high infra red camera measurement accuracy. Therefore, DLR developed a small emissivity determination probe, which is heated by the laser with a relatively low heat flux. The temperature of this emissivity determination probe is measured with the same infra red camera as used for the TMF test itself in order to determine the emissivity for this infra red camera. Additionally - in order to determine the absorption at the laser wave length - the temperature of the emissivity determination probe is measured by the pyrometer as described in section IIIE2. This

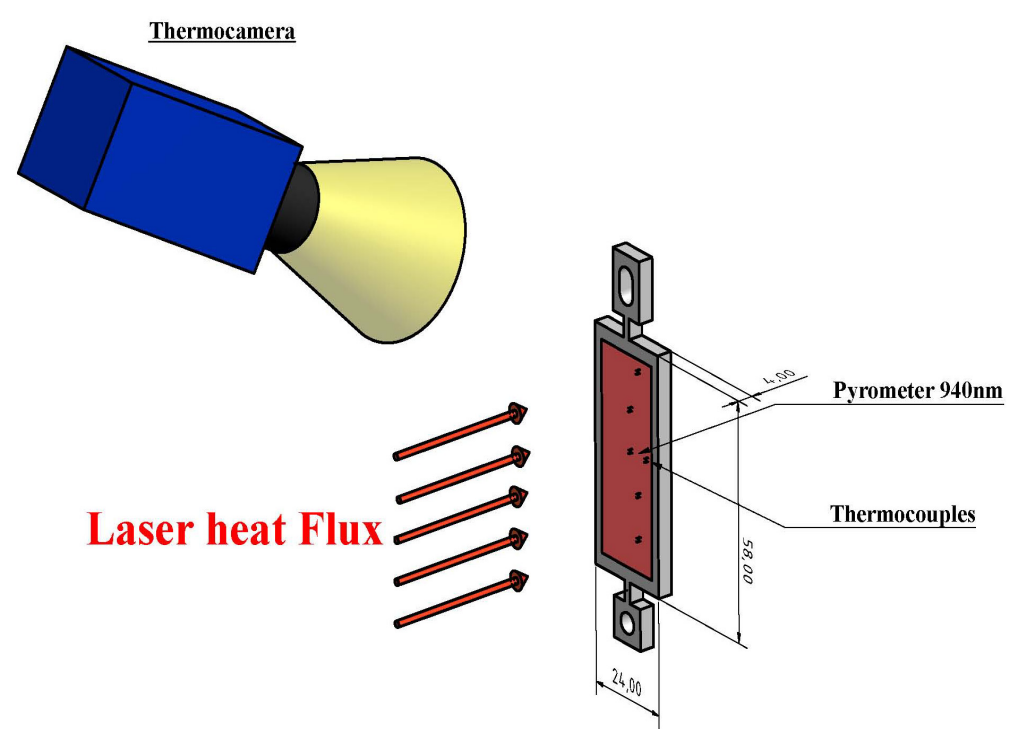

Figure 7: Emissivity determination probe with measurement equipment.

pyrometer is focused on the rear side centre of the panel. To avoid a possible influence of the laser radiation on the measured temperature, the laser is shielded at the rear side by a special ceramic plate with a low thermal conductivity.

\section{B. Governing Equations}

The emission of energy $M_{\lambda, T}$ in dependency on temperature and wavelength can be calculated by Planck's law:

with:

$$
M_{\lambda, T}=\frac{2 h c^{2}}{\lambda^{5}} \cdot \frac{1}{e^{\frac{h c}{k k T}}-1}
$$

\footnotetext{
$\lambda$ : wavelength $[\mathrm{m}]$

$k$ : Boltzmann constant $[\mathrm{J} / \mathrm{K}]$

$T$ : absolute temperature $[\mathrm{K}]$

$h$ : Planck constant [Js]

$c$ : speed of light $[\mathrm{m} / \mathrm{s}]$
}

For calculating the emitted power in a fixed wavelength range, equation (1) must be integrated for two measured temperatures. The first temperature is the one which can be derived from the optical measurement $T_{\text {meas,opt }}$. The second measured temperature which is used as the reference temperature $T_{\text {meas, ref }}$ can be extrapolated from the thermocouple measurement points. The emissivity on a certain wavelength range can then be determined by the integral quotient as given in equation (2). 


$$
\varepsilon=\frac{\int_{\lambda} M_{\lambda, T_{\text {meas }, \text { opt }}} d \lambda}{\int_{\lambda} M_{\lambda, T_{\text {meas }, \text { ref }}} d \lambda}
$$

\section{Measurement of the reference temperatures}

The emissivity determination probe is equipped with six thermocouples at defined positions. By using thermocouples with a diameter of $0.25 \mathrm{~mm}$, even transient processes can be resolved. The thermocouples are mounted with a $\mathrm{MgO}$ and $\mathrm{AlO}$ based ceramic bond ${ }^{\S \S \S}$ with a thermal conductivity similar to the base material (a nickel basis alloy). The positions of the thermocouples are chosen to allow for the determination of the thermal field inside the emissivity determination probe, including the thermal gradient between front and back face. This is obtained by the two thermocouples mounted in the centre, bonded in different depths. By assuming symmetry, it is possible to estimate the temperatures on the front and on the back face in the centre of the emissivity determination probe. These temperatures can then be used to calculate the emissivity at $3.99 \mu \mathrm{m}$ and the absorption at $940 \mathrm{~nm}$.

\section{Exemplary temperature measurement results (@1350K)}

Figure 8 illustrates the time-dependent evolution of the temperatures measured by the thermocouples inside the emissivity determination probe.
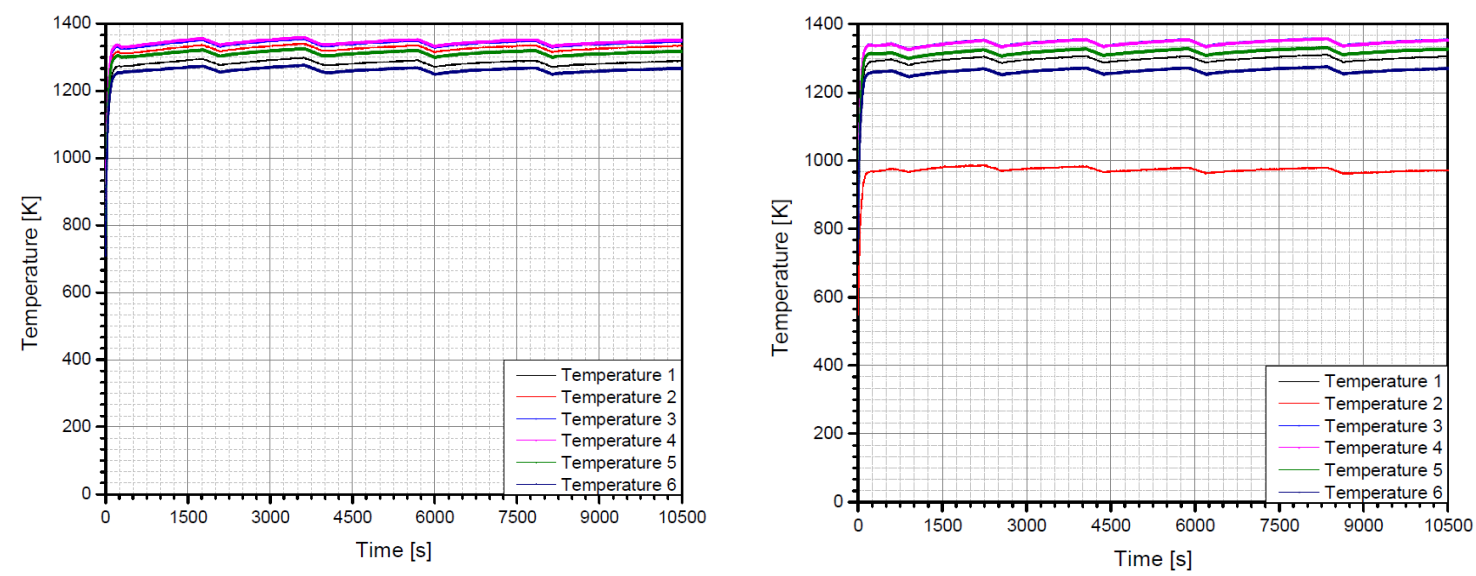

Figure 8: Temperature evolution of the emissivity determination probe. Left: Test 1; Right: Test 2.

In each emissivity determination test, the laser current is kept constant, leading to an almost constant laser power $(550 \mathrm{~W}$ for the $1350 \mathrm{~K}$ test). This leads to a nearly constant temperature at the surface of the emissivity testing probe. The slight cyclic behaviour of the temperatures as shown in Figure 8 is a result of a periodic activation of the compressor of the laser cooling system. This compressor cools down the continuously flowing cooling water for the laser head. When the laser is working at high power levels, the cooling system is operating in its design range and the compressor works continuously. However - for the tests with the emissivity determination probe at a relatively low laser power, the compressor is overdesigned. Therefore, the cooling water is cooled down to the lower limit temperature and the compressor is switched off. As the efficiency of the laser diodes increases for lower temperatures, this leads to a higher laser output power and as a result also to an increase of the maximal temperature of the emissivity determination probe. Once the compressor is switched off, the temperature of the cooling water increases again, leading to a decrease of both - the laser output power as well as the temperature of the emissivity determination probe. A continuous repetition of this process leads to the cyclic behaviour as visible in Figure 8 .

$\S \S \S$ URL: http://www.globalspec.com/FeaturedProducts/Detail/AremcoProducts/

CERAMABOND_571_COATS_SPECIALTY_CATALYTIC_CONVERTER/52075/0, [cited 16 July 2010] 


\section{E. Resulting emissivity values}

With the currently used acquisition rate of the infra red camera $(2 \mathrm{~Hz})$, the resolution of the transient heating phase of the emissivity determination test is too low to get reliable results. Therefore, the transient heating phase is excluded in the emissivity diagrams shown in Figure 9 and Figure 10. For further emissivity determination tests, an increase of the data acquisition rate of the infra red camera is planned which will then allow to determine the emissivity of the panel coating also for the initial phase of the test.

\section{Emissivity at the spectral range of the infra red} camera

In Figure 9, the time-dependent evolution of the measured emissivity at the wavelength of the infra red camera is shown (continuous lines). A small breakdown of the emissivity by about $5 \%$ can be observed in the time range between $1000 \mathrm{~s}$ and $2000 \mathrm{~s}$. Afterwards, the emissivity increases to an almost steady-state value of around $92-95 \%$. The emissivity determination test was terminated after $10500 \mathrm{~s}-$ a time the TMF panel will not survive undamaged at a temperature of $1350 \mathrm{~K}$. Figure 9 also includes the measurement uncertainty for the calculation (dotted lines). This measurement uncertainty is based on taking into account the measurement error of the thermocouples.

\section{Emissivity at the laser wavelength}

In Figure 10, the calculated absorption coefficient at the laser wavelength is illustrated (continuous lines). During the heating phase of the emissivity determination probe, the absorption coefficient cannot be calculated because of the exceeded lower measuring range of the used pyrometer $(700 \mathrm{~K})$.

The values on the left side of Figure 10 indicate an absorption of $85 \%$, which would result in a maximal heat flux for the TMF panel of around $7.5 \mathrm{MW} / \mathrm{m}^{2}$. This value increases over time to a value of $90 \%$ after 2000 $\mathrm{s}$, yielding a growth of the achievable heat flux up to $8.5 \mathrm{MW} / \mathrm{m}^{2}$. Figure 10 also includes the measurement uncertainty of the absorption (dotted lines) caused by the measurement error of the thermocouples. This leads to a variation of the emissivity of the panel coating of around $3 \%$.

\section{Exemplary TMF test results}

The test results as given in the following subsections will be used as validation data, which will be compared to numerical results in order to assess the suitability of numerical methods to analyze thermally loaded wall structures.

\section{A. 2d thermal field on the laser loaded surface of the TMF panel}

In Figure 11, the temperature field as taken by the infra red camera at the end of a heating cycle of

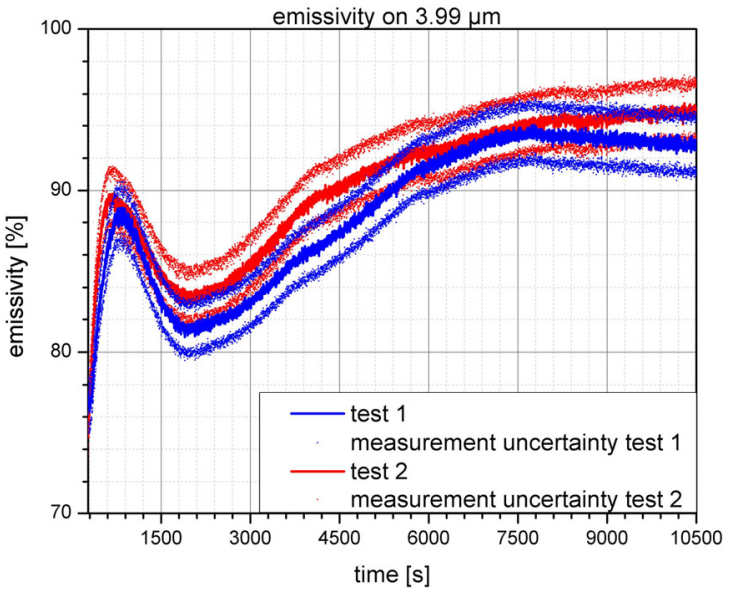

Figure 9: Emissivity of panel coating @1350 K in the spectral range of the infra red camera.

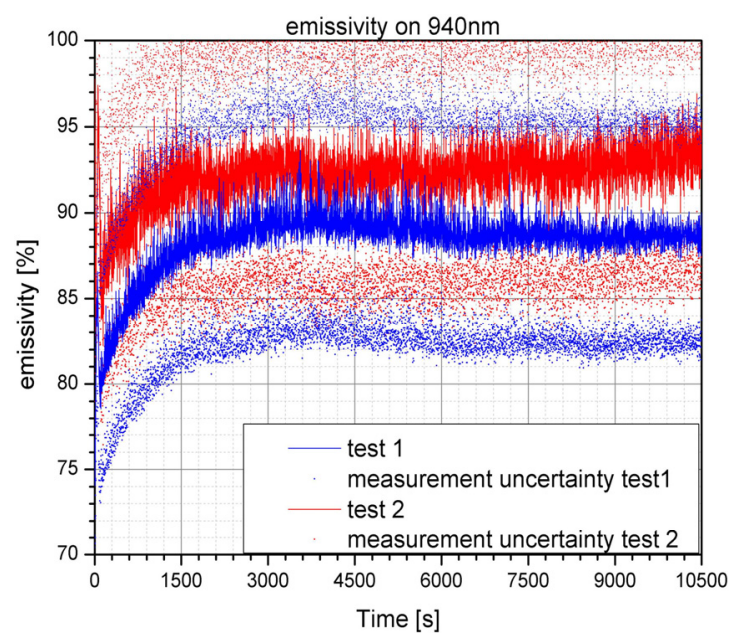

Figure 10: Emissivity of the panel coating @1350 $K$ at the laser wavelength.

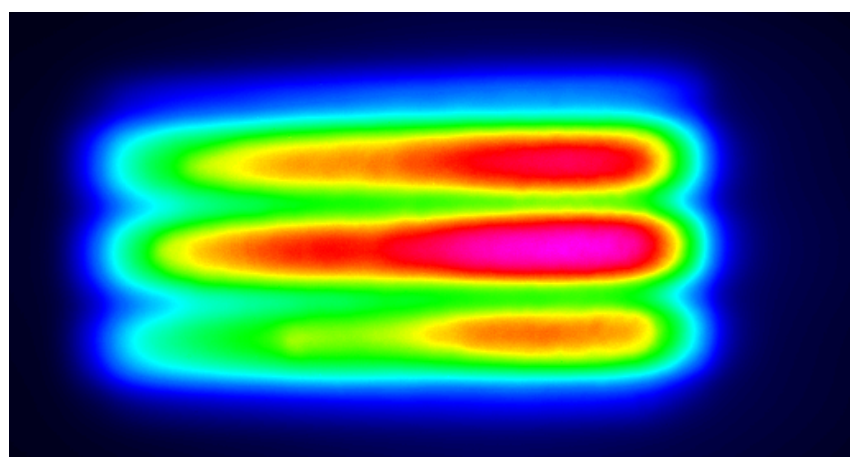

Figure 11: Picture taken by the infra red camera during a TMF panel test. 
the TMF panel is shown. The maximum temperature can be found at the end of the laser plateau.

\section{B. 2d deformation field on the laser loaded surface of the TMF panel}

In Figure 12, the out of plane deformation of the TMF panel during a laser loading cycle is shown.


Figure 12: Out-of plane deformation of the cooling channels during a TMF panel test (acquisition rate: $0.5 \mathrm{~Hz}$ ).

The maximal displacements shown in Figure 12 correspond to the maximal temperatures shown in Figure 11.

\section{Outlook}

Future TMF panel tests can be performed for the pre qualification of recently developed hot gas wall geometries (e.g. elastic liner ${ }^{12}$ and high aspect ratio cooling channels ${ }^{13}$ ), recently applied production technologies (e.g. brazing $^{14}$, laser welding ${ }^{15}$ and sandwich technology ${ }^{16}$ ), new materials (e.g. $\mathrm{CuCrNb}^{17}$ ), recently applied material production technologies (e.g. vacuum plasma spraying ${ }^{18}$ ) and/or recently applied thermal barrier coatings ${ }^{19}$ with respect to the cyclic thermo-mechanical fatigue of these wall structures, materials and/or coatings.

As the emissivity and the absorption of the TMF Panel coating are of fundamental interest for the whole test principle, the calculations based on experimental data will be performed to fit the emissivity and the absorption coefficients to the best values. Due to the lack of temperature measurements at the positions where both coefficients have to be determined, a thermal analysis of the structure is the only way to achieve the knowledge about their values at the highest possible accuracy.

\section{References}

${ }^{1}$ Riccius, J.; Zametaev, E.; Haidn, O. and de Boisvilliers, G., "Structural analysis of the cyclic loading of regeneratively cooled combustion chamber walls using 2d and 3d Finite Element Models," Deutscher Luft- und Raumfahrtkongress 2006; Braunschweig, Gernamy, 06-09 November 2006.

${ }^{2}$ Schwarz, W.; Schwub, S.; Quering, K.; Wiedmann, D.; Höppel, H. W.; and Göken, M., "Life prediction of thermally highly loaded components: Modelling the damage process of a rocket combustion chamber hot wall," Space Propulsion Conference 2010, San Sebastian, Spain, 02-05 May 2010.

${ }^{3}$ Bartsch, M.; Baufeld, B.; and Heinzelmann, M., "CMSX-4 with Thermal Barrier Coating under Thermal Gradient Mechanical Fatigue," 9th International Conference on Fatigue, 2006.

${ }^{4}$ Baufeld, B.; and Bartsch, M., "Temperature Measurement in Thermal Gradient Mechanical Fatigue Testing of Material Systems with Coatings," Proceedings of a Symposium sponsored by Engineering Conferences International, edited by Fuchs, G. E.; James, A. W.; Gabb, T.; McLean, M.; and Harada, H., Advanced Materials and Processes for Gas Turbines, 22 - 26 September 2002, p. $75-82$.

${ }^{5}$ Köhler B.; Noeske A.; Kindervater T.; Wessollek A.; Brand T.; and Biesenbach, J., "11 kW direct diode laser system with homogenized 55 x $20 \mathrm{~mm}^{2}$ Top-Hat intensity distribution," Photonics West; 2007. 
${ }^{6}$ Overton, G., "LASER-BEAM SHAPING: Diode-laser system yields $11 \mathrm{~kW}$ homogenized output," Laser Focus World, Volume 43, Issue 5, May 2005, URL: http://www.laserfocusworld.com/display_article/292380/12/ARTCL/none/News/LASERBEAM-SHAPING:-Diode-laser-system-yields-11-kW-homogenized-outpue [cited 02 August 2010].

${ }^{7}$ Brandl, V.; Hansel, K.; Kramer, R. and Schwede, H., "Calibration of Laser Power Meters in the Multikilowatt Range," Laser Beam Characterization, Instruments and Standard Test Procedures for Laser Beam and Optics Characterization, CHOCLAB II, Eureka project EU-2359, VDI Technology Center, June 2003.

${ }^{8}$ Sutton, M. A.; Orteu, J.-J.; and Schreier, H. W., "Image Correlation for Shape, Motion and Deformation Measurements: Basic Concepts, Theory and Applications," Springer-Verlag GmbH, 2009.

${ }^{9}$ Riccius, J.; Gernoth, A.; Suslova, E.; Böhm, C.; Zametaev, E.; Haidn, O.; Brummer, L.; Mewes, B.; Knab, O.; Terhardt, M.; and Hagemann, G., "TMF: Laser Application for a Close-to-Reality Simulation of Thermo-Mechanical Fatigue Processes in Rocket Engines," 2nd European Conference for Aerospace Sciences (EUCASS), 1-5 July, 2007.

${ }^{10}$ Gernoth, A.; Riccius, J.; Haidn, O.; Brummer, L.; Mewes, B.; and Quering, K., "TMF panel tests: close-to-reality simulation of thermo-mechanical fatigue processes in heat-loaded walls," 44th AIAA/ASME/SAE/ASEE Joint Propulsion Conference, 21-23 July, 2008.

${ }^{11}$ Riccius, J.; Zametaev, E. B.; Gernoth, A.; Schwarz, W.; and Keppeler, J., "A Laser plateau size optimization strategy for TMF tests," 3rd European Conference for Aerospace Sciences (EUCASS), 6-9 July, 2009.

${ }^{12}$ Immich, H.; Kretschmer, J.; and Preclik, D., "Thrust Chamber Technology Developments for Future Launch Vehicle Liquid Rocket Engines," 37th AIAA/ASME/SAE/ASEE Joint Propulsion Conference \& Exhibit, 2001.

${ }^{13}$ Woschnak, A.; Suslov, D.; and Oschwald, M., "Experimental and Numerical Investigations of Thermal Stratification Effects," 39th AIAA/ASME/SAE/ASEE Joint Propulsion Conference, 20 - 23 July 2003.

${ }^{14}$ Preclik, D.; Hagemann, G.; and Kretschmer, J., "Technology Efforts towards Low-Cost Thrust Chambers," 37th AIAA/ASME/SAE/ASEE Joint Propulsion Conference \& Exhibit, 20-23 July 2003.

${ }^{15}$ Damgaard, T.; Brox, L.; and Hallberg, M., "Demonstration of a Laser Welded Channel Wall Nozzle - Vulcain 2 Scale," 42nd AIAA/ASME/SAE/ASEE Joint Propulsion Conference \& Exhibit, 2006.

${ }^{16}$ Emvin, P., "The V2+ Nozzle Extension Demo: A milestone on the route to sandwich nozzle production," 57th International Astronautical Congress, 2-6 October, 2006.

${ }^{17}$ Ellis, D. L., "GRCop-84: A High-Temperature Copper Alloy for High-Heat-Flux Applications," NASA/TM-2005-213566, Glenn Research Center, Cleveland, Ohio, 2005.

${ }^{18}$ Thomas, J. L.; Cornu, D.; Choulant, M.; Verdy, C.; and Coddet, C., "Vacuum Plasma Spray Process applied to high thickness components for Liquid Rocket Engine," 41st AIAA/ASME/SAE/ASEE Joint Propulsion Conference \& Exhibit, 10 - 13 July 2005.

${ }^{19}$ Winterfeldt, L.; Laumert, B.; Tano, R.; Blasi, R.; and Hagemann, G., "Redesign of the Vulcain 2 Nozzle Extension," 41st AIAA/ASME/SAE/ASEE Joint Propulsion Conference \& Exhibit, 10 - 13 July 2005. 